\title{
Distribution of Missing Data
}

Figures showing the distribution of missing data for each questionnaire type; pre, post, retention and control.

\section{Pre}
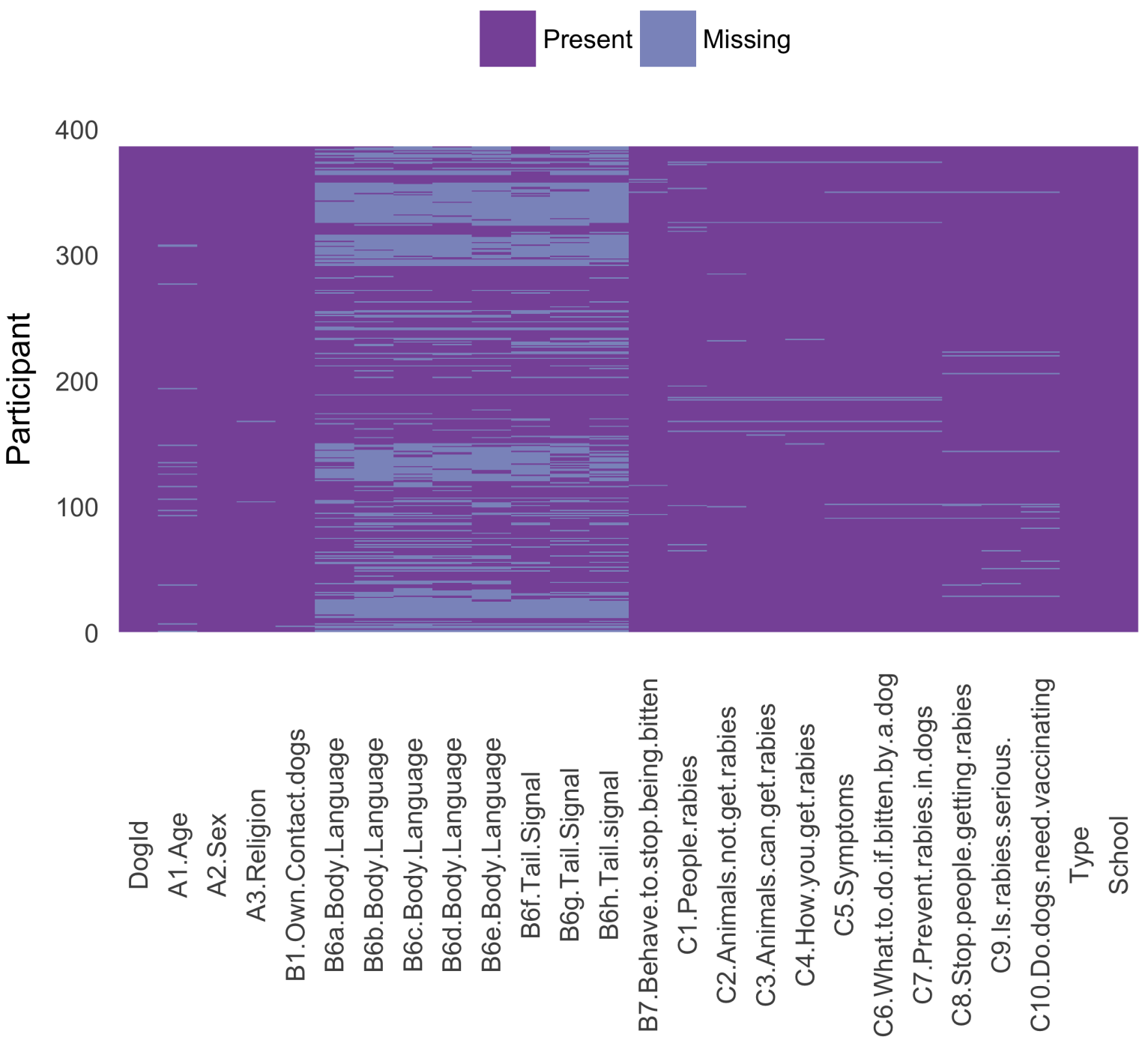


\section{Post}

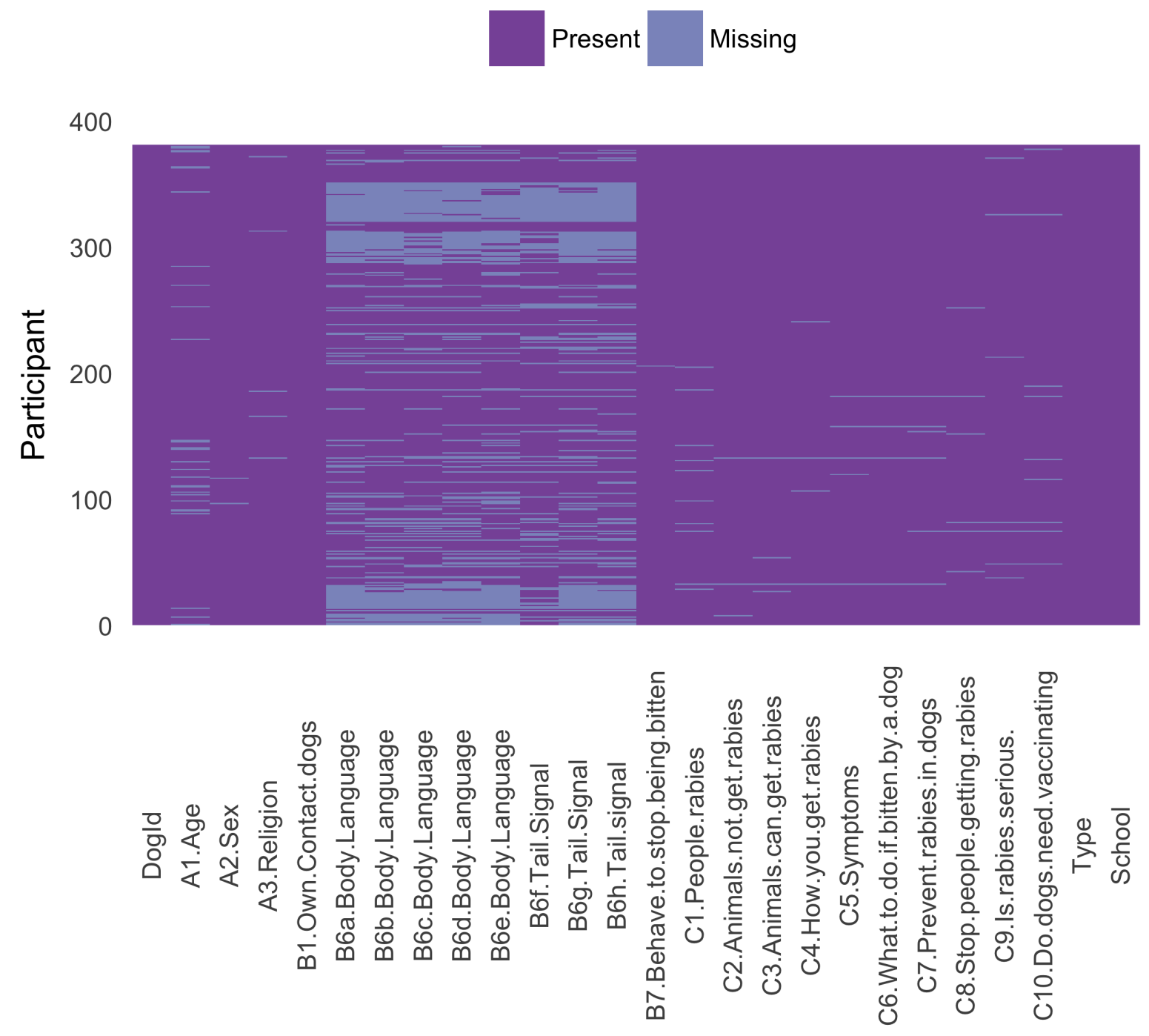




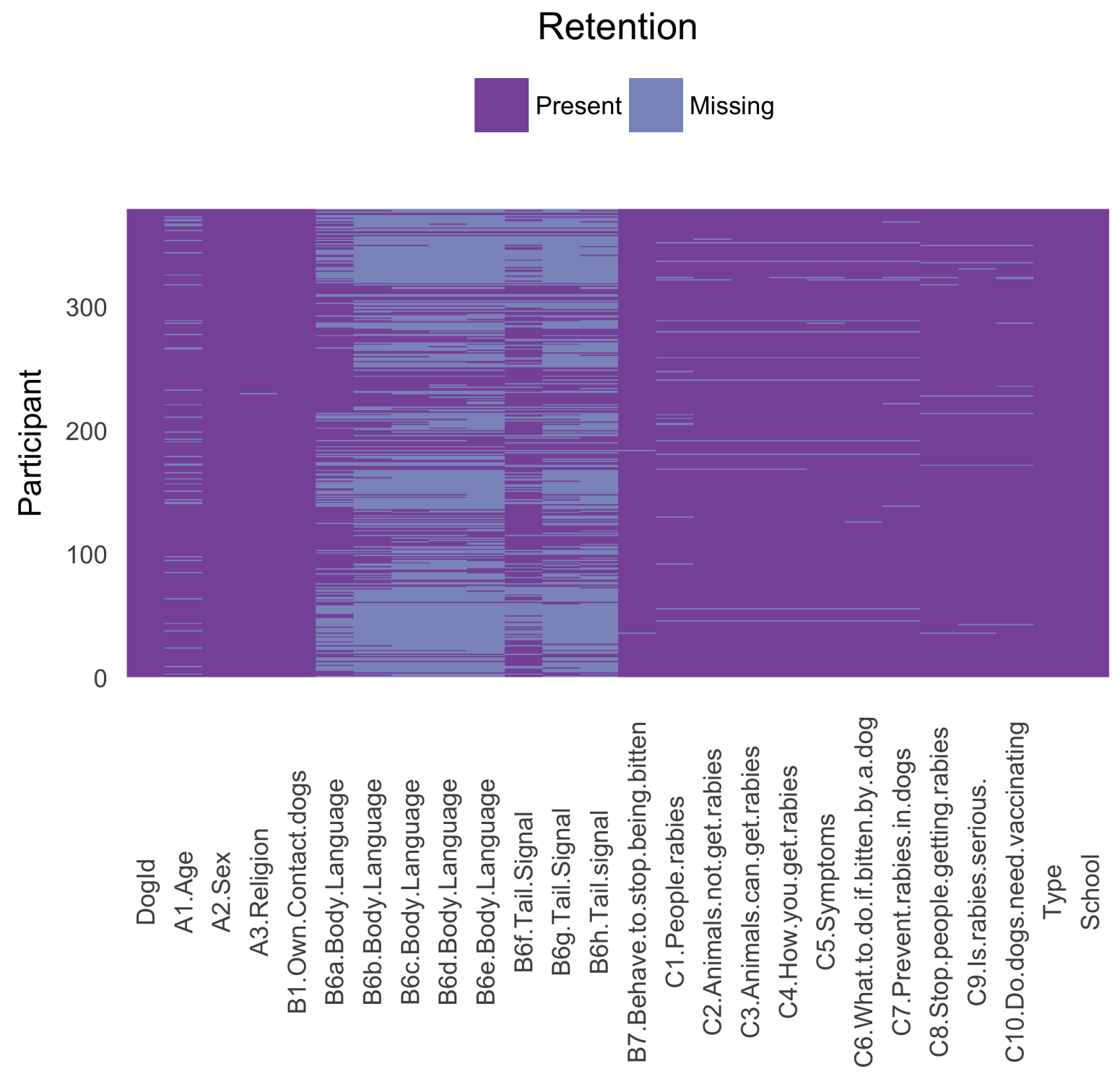




\section{Control}

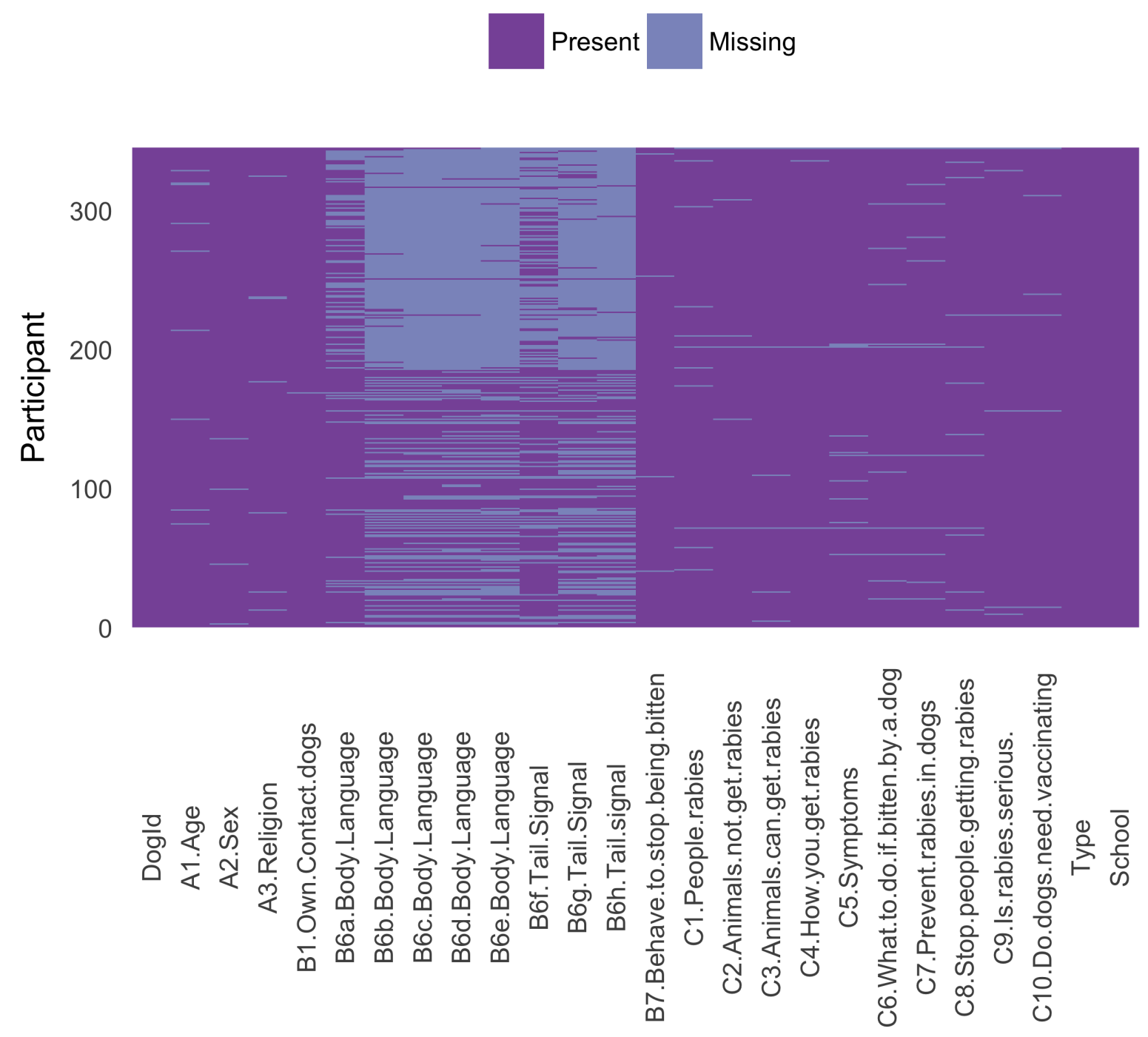

